\title{
Alterations of NO Synthase Isoforms in Brain and Kidney of Rats With Genetic and Salt Hypertension
}

\author{
S. HOJNÁ ${ }^{1}$, J. KUNE $\check{S}^{1}$, J. ZICHA ${ }^{1}$ \\ ${ }^{1}$ Cardiovascular Research Center, and Institute of Physiology, Academy of Sciences of the Czech \\ Republic, Prague, Czech Republic
}

Received August 18, 2010

Accepted September 1, 2010

\begin{abstract}
Summary
Both brain and peripheral nitric oxide (NO) play a role in the control of blood pressure and circulatory homeostasis. Central NO production seems to counteract angiotensin II-induced enhancement of sympathetic tone. The aim of our study was to evaluate NO synthase (NOS) activity and protein expression of its three isoforms - neuronal (nNOS), endothelial NOS (eNOS) and inducible (iNOS) - in two brain regions involved in blood pressure control (diencephalon and brainstem) as well as in the kidney of young adult rats with either genetic (12-week-old SHR) or saltinduced hypertension (8-week-old Dahl rats). We have demonstrated reduced nNOS and iNOS expression in brainstem of both hypertensive models. In SHR this abnormality was accompanied by attenuated NOS activity and was corrected by chronic captopril treatment which prevented the development of genetic hypertension. In salt hypertensive Dahl rats nNOS and iNOS expression was also decreased in the diencephalon where neural structures important for salt hypertension development are located. As far as peripheral NOS activity and expression is concerned, renal eNOS expression was considerably reduced in both genetic and salt-induced hypertension. In conclusions, we disclosed similar changes of NO system in the brainstem (but not in the diencephalon) of rats with genetic and salt-induced hypertension. Decreased nNOS expression was associated with increased blood pressure due to enhanced sympathetic tone.
\end{abstract}

\section{Key words}

Brainstem • Diencephalon • Kidney • NO synthase • Genetic hypertension

\section{Corresponding author}

S. Hojná, Institute of Physiology AS CR, Vídeňská 1083, 14220

Prague 4, Czech Republic. E-mail: silvie.hojna@post.cz

\section{Introduction}

The main role of nitric oxide (NO) in blood pressure maintenance is to counterbalance the major pressor system, namely sympathetic nervous system, not only on the periphery but also in the central nervous system. It is evident that sympathetic activity can be increased by the blockade of central NO production (Gerová et al. 1995, Tseng et al. 1996) or decreased by the local application of NO donors in discrete brain nuclei (Lewis et al. 1991, Horn et al. 1994) indicating that NO may affect sympathetic activity at multiple sites in the brain. Although NO system is moderately upregulated in salt-hypertensive Dahl rats, it is unable to fully counterbalance sympathetic hyperactivity in hypertensive animals (Zicha et al. 2001). The same was true in genetically hypertensive rats (Kuneš et al. 2002).

It has been demonstrated that NO plays an important role in various physiological systems coordinated by the brain including the regulation of autonomic functions (Krukoff 1999) and blood pressure (Dampney et al. 2005). Cabrera et al. (1996) reported that central depressor role of endogenous NO is attenuated in SHR, whereas Kagiyama et al. (1998) observed enhanced depressor response to NO donors microinjected into rostral-ventrolateral medulla in the brainstem of SHR. Recently, several authors have demonstrated an increased nitric oxide synthase (NOS) activity and/or enhanced expression of neuronal NOS (nNOS) in hypothalamus and in brainstem of SHR with established hypertension (Plochocka-Zulinska and Krukoff 1997, Qadri et al. 2003, Edwards et al. 2004). Moreover, central nervous system and kidneys were suggested as two major sites for salt-sensing sensors (Orlov and Mongin 2007). On the 
other hand, much less attention has been paid to identification, which particular NOS isoforms in the brain and in the kidneys would be the major denominator of blood pressure regulation in SHR and Dahl salt-sensitive rats.

The aim of the present study was to search for possible alterations of NO production in the brain and the kidney of Dahl salt-sensitive and SHR rats in which we have previously confirmed high sympathetic tone (Zicha et al. 2001, Paulis et al. 2007). An attempt was made to investigate not only the alterations accompanying the induction of salt hypertension in Dahl rats but also the changes associated with the prevention of spontaneous hypertension development following chronic ACE inhibitor administration to SHR. We therefore measured the total NOS activity together with the activity of neuronal NOS isoform and protein expression of all three isoforms - neuronal, inducible and endothelial NOS (nNOS, iNOS and eNOS, respectively) in specific regions of the rat brain involved in BP control brainstem and diencephalon. We also determined NOS activity and expression in the kidney.

\section{Materials and Methods}

\section{Animals}

Young adult (12-week-old) male spontaneously hypertensive (SHR, $\mathrm{n}=18)$ and age-matched normotensive Wistar-Kyoto (WKY, $\mathrm{n}=17$ ) rats as well as 8-week-old female Dahl/Rapp salt-sensitive (DS, $n=15$ ) and salt-resistant $(\mathrm{DR}, \mathrm{n}=13)$ rats were obtained from our own breeding colonies (Institute of Physiology, AS CR, Prague) at the time of weaning (at the age of 4 weeks). Animals of all experimental groups were housed under standard laboratory conditions (temperature $23 \pm 1{ }^{\circ} \mathrm{C}$, 12-h light/dark cycle) and drank tap water ad libitum. SHR and WKY were fed a standard pellet diet (ST-1), half of the animals being treated with captopril (CAP; $100 \mathrm{mg} / \mathrm{kg} /$ day in the drinking fluid) for 8 weeks since weaning. Dahl rats were fed either low-salt (LS; $0.3 \%$ $\mathrm{NaCl}$ ) or high-salt ( $\mathrm{HS} ; 8.0 \% \mathrm{NaCl}$ ) diet for 4 weeks since weaning.

All procedures and experimental protocols, which were approved by the Ethical Committee of the Institute of Physiology AS CR, conform to European Communities Council Directive (86/609/EC) on Animal Protection and Guidelines on Research Animal Use.

At the end of the experiment, blood pressure was measured by a direct puncture of the carotid artery under light ether anesthesia using a pressure transducer (Statham, Hato Ray, USA) and recorder (HewlettPackard, Andover, USA). Thereafter animals were sacrificed by decapitation, heart, kidney and brain were removed, areas of interest (diencephalon and brainstem) were dissected and assayed for NOS activity and protein expression by Western blotting.

\section{Experimental protocol}

After sacrifice the diencephalon and brainstem were dissected, as previously described (Hojná et al. 2007). Shortly, after decapitation the brain was quickly removed from the cranium and $2 \mathrm{~mm}$ thick frontal slice (AP 0 to AP-2) was cut. A ventromedial block of tissue dissected $3 \mathrm{~mm}$ from the ventral tissue border and $1.5 \mathrm{~mm}$ bilaterally from the midline was removed and used for further analyses. This block contains mainly the medial preoptic-anterior hypothalamic region of the diencephalon (lamina terminalis, median preoptic nucleus, anterior hypothalamic nucleus, suprachiasmatic nucleus, supraoptic nucleus, paraventricular nucleus) and anterior part of the region of the tuber cinerum (ventromedial nucleus). Tissue containing subfornical organ was dissected separately from the ventral side of fimbria and analyzed together with the "hypothalamic", block of the diencephalon. Total amount of tissue sample was about 30-40 mg. The brainstem with cerebellum was separated from the rest of the brain and a block of brainstem containing rostral-ventrolateral medulla and caudal posterior part of fossa rhomboidea (weighing about 80-100 mg) was dissected. $20 \%$ (wt/vol) homogenates from brain tissue samples were prepared in ice-cold buffer containing $50 \mathrm{mmol} / \mathrm{l}$ Tris- $\mathrm{HCl}$ (pH 7.4) supplemented with protease inhibitor cocktail (Sigma, St. Louis, USA). Fresh homogenates were also prepared from the kidney of all experimental animals. The homogenates were centrifuged at $5500 \mathrm{x}$ g for $15 \mathrm{~min}$ at $4{ }^{\circ} \mathrm{C}$ and obtained supernatants were re-centrifuged at $14000 \mathrm{x} \mathrm{g}$ for $15 \mathrm{~min}$. Protein concentrations in supernatants were analyzed using the Lowry method with bovine serum albumin (Sigma) as a standard.

\section{NO synthase activity}

Total activity of NOS enzyme was determined by measuring the ability of tissue homogenates to convert $\mathrm{L}-\left[{ }^{3} \mathrm{H}\right]$ arginine to $\mathrm{L}-\left[{ }^{3} \mathrm{H}\right]$ citrulline (Amersham Biosciences, Buckinghamshire, UK), as previously described by Bredt and Snyder (1990) with minor modifications (Pecháňová et al. 1997). The enzymatic 
activity of neuronal NOS isoform was determined using S-methyl-L-thiocitrulline (SMTC; Sigma) as a selective inhibitor of nNOS enzyme. The concentration of SMTC $10^{-4} \mathrm{M}$ has been chosen on the basis of preliminary experiments. S-methyl-L-thiocitrulline in this concentration was able to inhibit mainly the activity of nNOS.

\section{Western blotting}

All tissue homogenates were analyzed by Western blot according to previously published methods (Hojná et al. 2007). An equal amounts of proteins for each sample ( $70 \mu \mathrm{g}$ per well) were denatured for $5 \mathrm{~min}$ and then loaded onto $10 \%$ SDS polyacrylamide gel in Tris-glycine electrophoresis buffer $(25 \mathrm{mmol} / 1$ Tris, 250 $\mathrm{mmol} / \mathrm{l}$ glycine and $0.25 \% \mathrm{SDS}$ ). After electrophoresis, the proteins were electro-transferred onto nitrocellulose membrane (Pierce, Rockford, USA) in Tris-glycine-SDSmethanol buffer at constant current $60 \mathrm{~mA}$ overnight, using the Bio Rad system (Richmond, USA). After this step, the membrane was stained with Ponceau S (Sigma) to verify the uniformity of protein load and transfer efficiency across the test samples. Then the membrane was blocked for $6 \mathrm{~h}$ at room temperature using $5 \%$ nonfat dry milk in TBS-T before incubation with appropriate primary antibodies. Three primary antibodies against particular NOS isoforms were used: (a) rabbit polyclonal anti-nNOS antibody (1:400 dilution, Transduction Laboratories, Lexington, USA), (b) rabbit polyclonal anti-eNOS antibody, and (c) rabbit polyclonal anti-iNOS antibody (both 1:1000 dilution, Santa Cruz Biotechnology, Santa Cruz, CA). The membrane was incubated with diluted primary antibody in TBS-T-2 \% milk overnight at $4{ }^{\circ} \mathrm{C}$, then washed in TBS-T and finally incubated with a goat anti-rabbit secondary antibody (1:20000 dilution) conjugated with horseradish peroxidase (Pierce) for $1 \mathrm{~h}$ at room temperature. Immunocomplexes were visualized by chemiluminescent detection kit (Pierce). Optical density of respective bands was quantified by a densitometric scanning of the membranes using Aida software. Data were expressed in percentage of values obtained in the same assay in appropriate control animals, i.e. WKY rats for spontaneous hypertension and DR rats fed a high-salt diet (DR-HS) for salt-induced hypertension.

\section{Statistical analysis}

The data from both experiments were analyzed by 2-way ANOVA with strain and either treatment (CAP) or diet (LS, HS) as the main factors. When an interaction was significant, Bonferroni's method was used to pairwise comparisons. A value of $\mathrm{P}<0.05$ was considered statistically significant. The data are expressed as the mean \pm S.E.M. Statistical analyses were carried out with JMP (version 8, SAS Institute Inc., Cary, NC).

\section{Results}

\section{Basic parameters}

Blood pressure of 12-week-old spontaneously hypertensive rats was significantly higher in comparison with age-matched Wistar-Kyoto controls (Table 1). Captopril has lowered blood pressure in both strains, the effect being more pronounced in SHR. Elevated blood pressure of SHR was accompanied by a greater relative heart weight, while relative kidney weight was unchanged compared to WKY rats. Chronic captopril treatment decreased relative heart weight in both strains, but increased relative kidney weight in WKY only (Table 1).

The effect of high salt intake was evident in 8-week-old Dahl salt-sensitive rats in which blood pressure and relative organ weights were significantly higher in comparison with DS rats fed a low-salt diet. On the contrary, in Dahl salt-resistant rats high salt intake increased only the relative heart and kidney weights but not their blood pressure (Table 2).

\section{Central NO system of genetically hypertensive rats}

Total NOS enzymatic activity in the brainstem of SHR rats was significantly decreased as compared to WKY rats (Fig. 1). The same effect was observed when only nNOS activity was measured as a reduction of total NOS activity in the presence of SMTC $\left(10^{-4} \mathrm{M}\right)$. This was in agreement with a lower protein expression of nNOS in SHR as compared to WKY rats. While protein expression of eNOS in the brainstem was not changed in any experimental group, SHR rats tended to a lower expression of iNOS in comparison with the controls (Fig. 1). Chronic captopril administration increased nNOS and iNOS expression in the brainstem in both experimental groups, the effect being more pronounced in SHR rats. On the other hand, there were no significant changes in protein expression of any NOS isoform in the diencephalon of SHR (Fig. 2). These data were in agreement with the absence of significant differences in both total NOS and specific nNOS enzymatic activity in the same region. 
Table 1. Body weight (BW), relative heart (HW/BW) and kidney (KW/BW) weights as well as systolic (SBP), diastolic (DBP) and mean arterial (MAP) blood pressure in young adult spontaneously hypertensive rats (SHR) and Wistar-Kyoto (WKY) which were untreated or treated with captopril (CAP) for 8 weeks.

\begin{tabular}{lccccccc}
\hline & $\begin{array}{c}\text { WKY } \\
(\mathbf{n = 9})\end{array}$ & $\begin{array}{c}\text { WKY-CAP } \\
\mathbf{( n = 8 )}\end{array}$ & $\begin{array}{c}\text { SHR } \\
(\mathbf{n = 9})\end{array}$ & $\begin{array}{c}\text { SHR-CAP } \\
(\mathbf{n = 9})\end{array}$ & $\begin{array}{c}\text { Strain } \\
\mathbf{P =}\end{array}$ & $\begin{array}{c}\text { Treatment } \\
\mathbf{P}=\end{array}$ & $\begin{array}{c}\text { Strain x } \\
\text { Treatment }\end{array}$ \\
\hline$B W(g)$ & $271 \pm 5$ & $232 \pm 11^{*}$ & $255 \pm 7^{*}$ & $221 \pm 8$ & 0.076 & $<0.0001$ & 0.78 \\
$H W / B W(m g / 100 g$ b.w.) & $253 \pm 2$ & $230 \pm 6^{*}$ & $337 \pm 6^{*}$ & $274 \pm 4^{\#+}$ & $<0.0001$ & $<0.0001$ & 0.0002 \\
$K W / B W(m g / 100 g$ b.w.) & $746 \pm 8$ & $782 \pm 9^{*}$ & $733 \pm 8$ & $730 \pm 16^{+}$ & 0.006 & 0.14 & 0.10 \\
$S B P(m m ~ H g)$ & $138 \pm 5$ & $131 \pm 7$ & $187 \pm 6^{*}$ & $128 \pm 9^{\#}$ & 0.002 & $<0.0001$ & 0.0006 \\
$M A P(m m ~ H g)$ & $102 \pm 4$ & $78 \pm 4^{*}$ & $143 \pm 5^{*}$ & $91 \pm 7^{\#}$ & $<0.0001$ & $<0.0001$ & 0.012 \\
$D B P(m m ~ H g)$ & $81 \pm 4$ & $61 \pm 5^{*}$ & $109 \pm 5^{*}$ & $68 \pm 6^{\#}$ & 0.001 & $<0.0001$ & 0.034 \\
\hline
\end{tabular}

Data were analyzed by 2 -way ANOVA and they are means \pm S.E.M., ${ }^{*} p<0.05$ versus WKY, ${ }^{\#} p<0.05$ versus SHR, ${ }^{+} p<0.05$ versus WKYCAP.

Table 2. Body weight (BW), relative heart (HW/BW) and kidney (KW/BW) weights as well as systolic (SBP), diastolic (DBP) and mean arterial (MAP) blood pressure in Dahl salt-sensitive (DS) and salt-resistant (DR) rats fed either a low-salt diet (LS, $0.3 \% \mathrm{NaCl})$ or a high-salt diet (HS, $8 \% \mathrm{NaCl})$.

\begin{tabular}{|c|c|c|c|c|c|c|c|}
\hline & $\begin{array}{c}\mathrm{DR} / \mathrm{LS} \\
(\mathrm{n}=6)\end{array}$ & $\begin{array}{c}\mathrm{DR} / \mathrm{HS} \\
(\mathrm{n}=7)\end{array}$ & $\begin{array}{c}\mathrm{DS} / \mathrm{LS} \\
(\mathrm{n}=7)\end{array}$ & $\begin{array}{c}\mathrm{DS} / \mathrm{HS} \\
(\mathrm{n}=8)\end{array}$ & $\begin{array}{l}\text { Strain } \\
\mathbf{P}=\end{array}$ & $\begin{array}{l}\text { Diet } \\
\mathbf{P}=\end{array}$ & $\begin{array}{c}\text { Strain } \times \text { Diet } \\
\quad \mathbf{P}=\end{array}$ \\
\hline$B W(g)$ & $157 \pm 1$ & $162 \pm 4$ & $174 \pm 2 *$ & $176 \pm 4 *$ & $<0.0001$ & 0.27 & 0.66 \\
\hline$H W / B W(m g / 100 g$ b.w.) & $296 \pm 3$ & $327 \pm 4^{\#}$ & $304 \pm 5$ & $424 \pm 17^{\#^{*}}$ & $<0.0001$ & $<0.0001$ & 0.0003 \\
\hline$K W / B W(m g / 100 g$ b.w. $)$ & $717 \pm 18$ & $1011 \pm 21^{\#}$ & $686 \pm 18$ & $1169 \pm 47^{\#^{*}}$ & 0.057 & $<0.0001$ & 0.007 \\
\hline $\mathrm{SBP}(\mathrm{mm} \mathrm{Hg})$ & $130 \pm 2$ & $139 \pm 4$ & $144 \pm 3 *$ & $194 \pm 5^{\#^{*}}$ & $<0.0001$ & $<0.0001$ & $<0.0001$ \\
\hline$M A P(m m ~ H g)$ & $109 \pm 2$ & $116 \pm 6$ & $123 \pm 3 *$ & $156 \pm 4^{\#^{*}}$ & $<0.0001$ & $<0.0001$ & 0.005 \\
\hline$D B P(m m ~ H g)$ & $85 \pm 2$ & $94 \pm 6$ & $104 \pm 3 *$ & $126 \pm 5^{\#^{*}}$ & $<0.0001$ & 0.002 & 0.14 \\
\hline
\end{tabular}

Data were analyzed by 2-way ANOVA and they are means \pm S.E.M., $* \mathrm{p}<0.05$ versus $\mathrm{DR},{ }^{\#} \mathrm{p}<0.05$ versus LS.

\section{Central NO system of salt hypertensive rats}

In brainstem of Dahl rats with a salt-induced hypertension was a similar situation as in SHR brainstem (Fig. 3). Reductions in protein expression of nNOS and iNOS isoforms were found in hypertensive DS rats fed a high-salt diet in comparison with DR rats on the same diet. Contrary to spontaneous hypertension, salt-induced hypertension in DS rats was also characterized by a reduced expression of these two isoforms in the diencephalon (Fig. 4). While a high dietary $\mathrm{NaCl}$ intake caused a decrease in protein expression of nNOS and iNOS isoforms of Dahl salt-sensitive rats in both brain regions, there were either no or opposite changes of protein expression in Dahl salt-resistant rats. Moreover, no strain- or diet-dependent differences in eNOS expression have been disclosed in either brain region. Surprisingly, changes in protein expression did not correspond to total NOS enzymatic activity in any examined brain region of Dahl rats (Fig. 3 and 4).

\section{Peripheral NO system in hypertensive rats}

The expression of eNOS was substantially reduced in the kidney of SHR compared to WKY rats and this difference was not influenced by chronic captopril treatment (Fig. 5). Similar observation was also made in DS rats which had significantly decreased eNOS expression in their kidney even under the conditions of low-salt intake. Salt-induced hypertension in DS rats was associated with a further decrease of protein expression of eNOS that was accompanied by a downregulation of iNOS expression. There were no significant differences in renal nNOS expression between hypertensive and normotensive rats of either strain (data not shown). However, total NOS activity in renal homogenates did not show any major changes between experimental groups. 


\section{Brainstem}

Total NOS activity

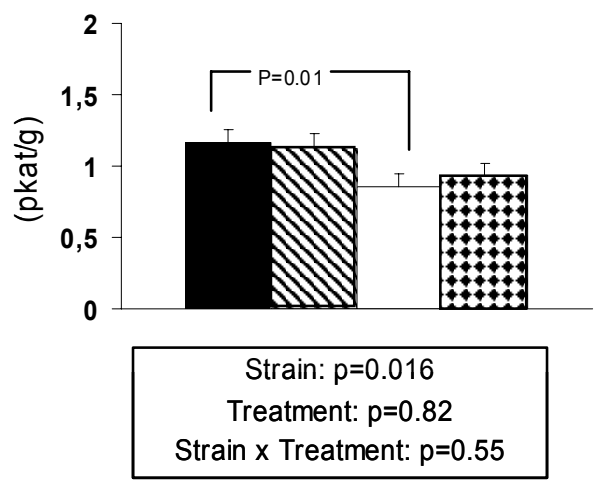

nNOS activity

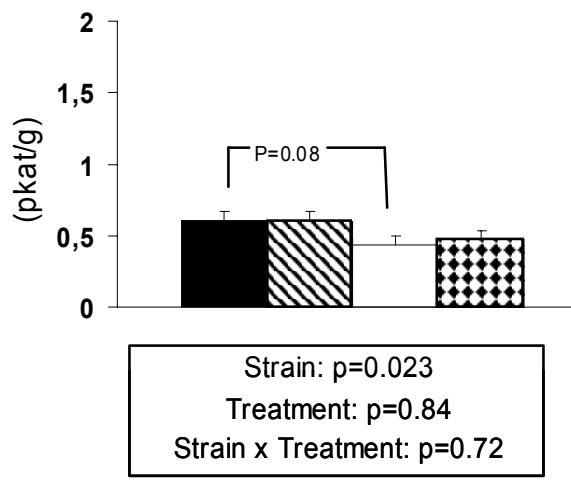

NOS protein expression

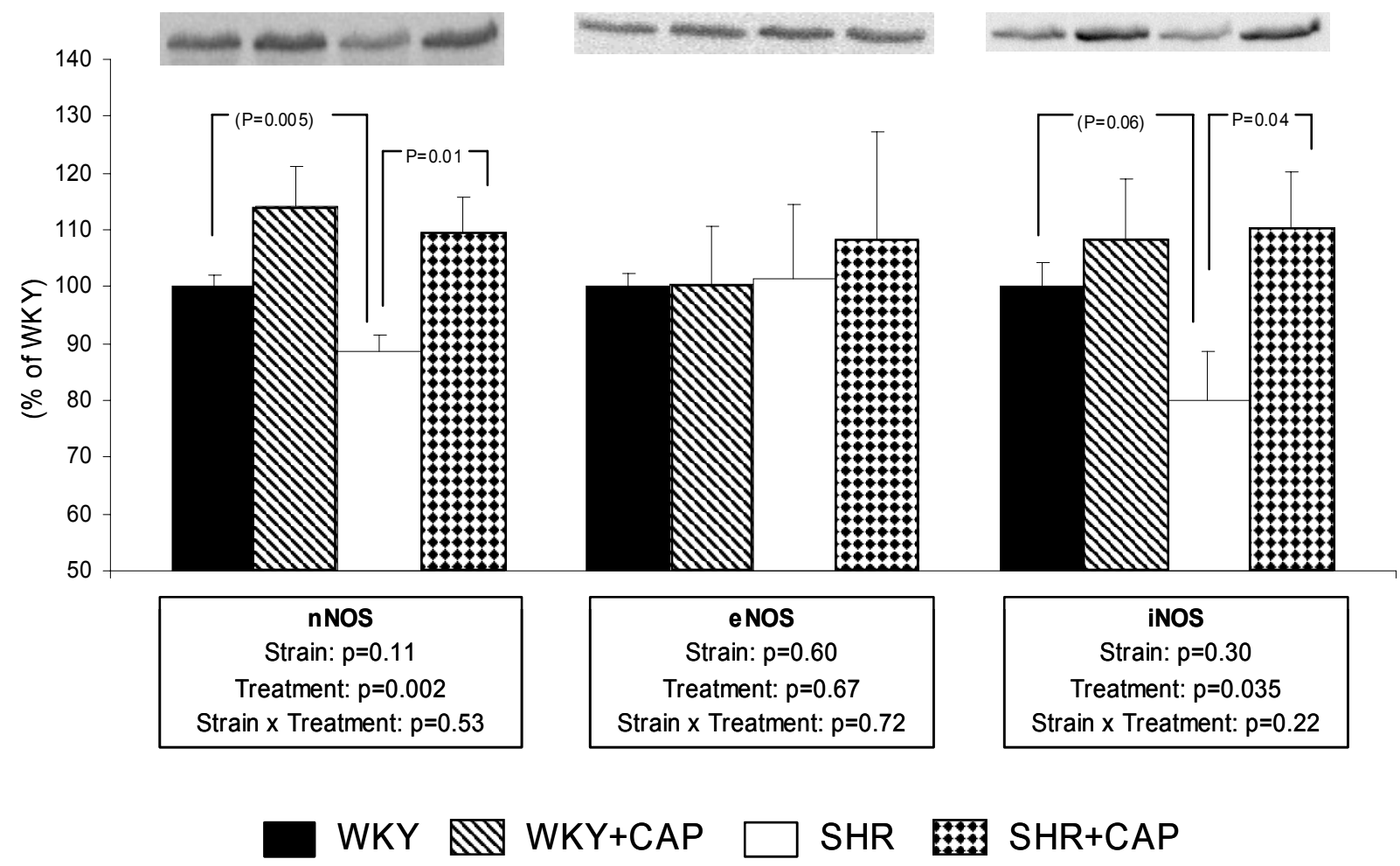

Fig. 1. Total NOS activity, neuronal NOS activity and protein expression of neuronal (nNOS), endothelial (eNOS) and inducible (iNOS) isoforms in brainstem isolated from Wistar-Kyoto (WKY) rats, spontaneously hypertensive rats (SHR) as well as from WKY and SHR chronically treated with captopril (WKY+CAP, SHR+CAP). Data are means \pm S.E.M. from 6-8 animals in each group. Protein expressions are expressed in percentage of WKY values obtained in the same assay. 


\section{Diencephalon}

Total NOS activity

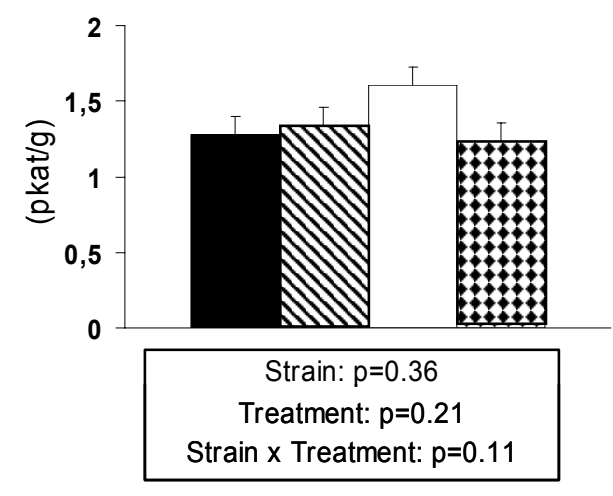

nNOS activity

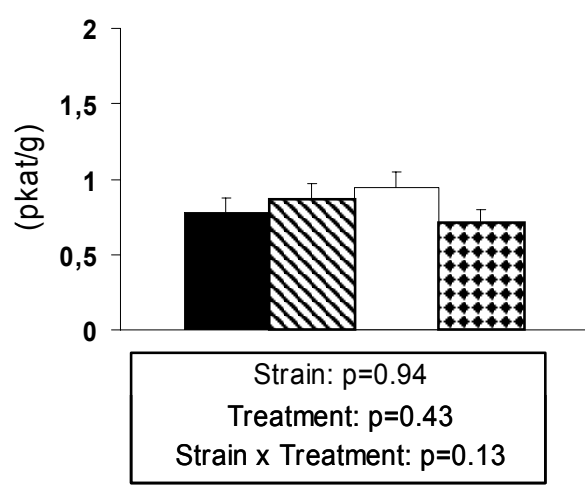

NOS protein expression

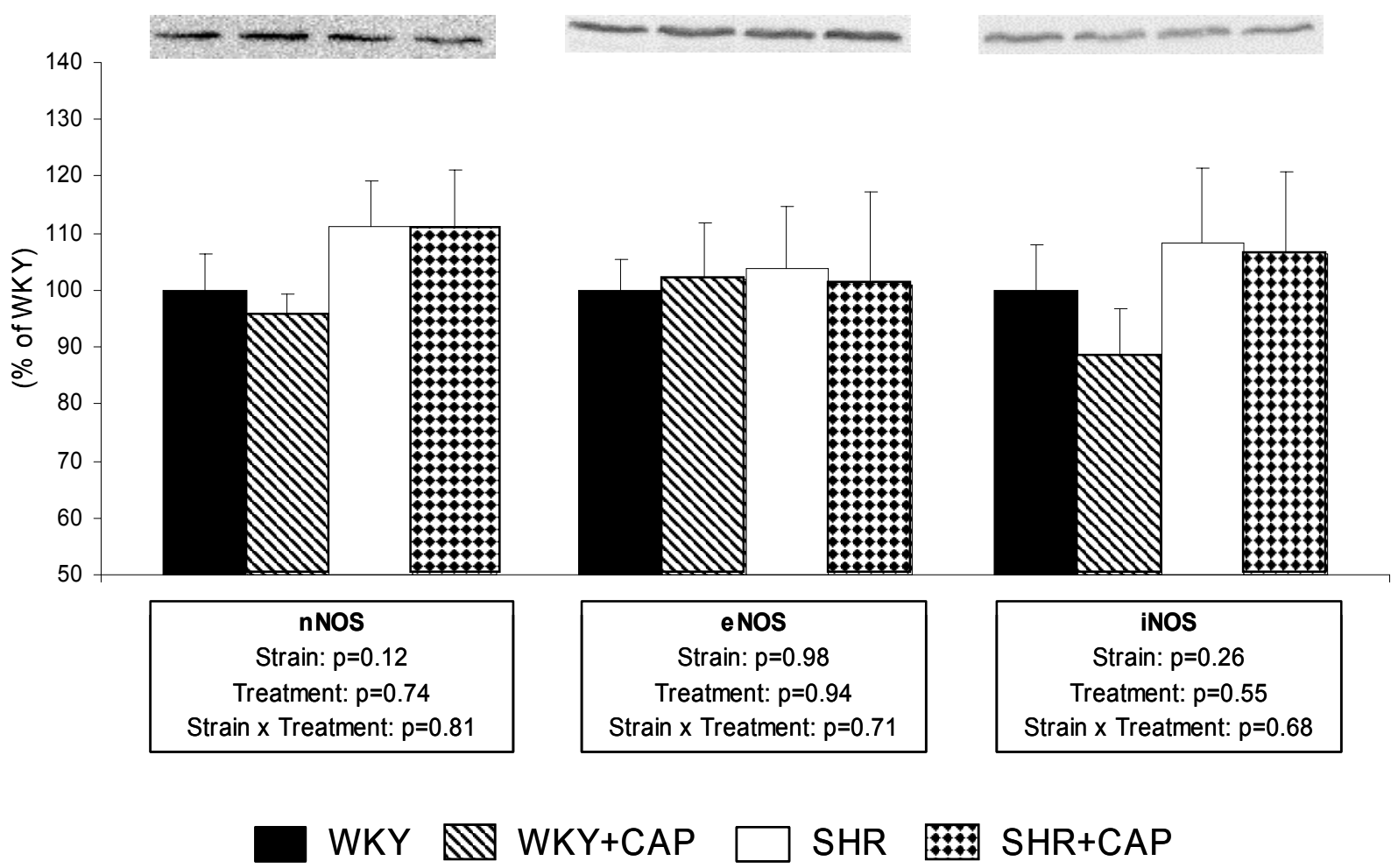

Fig. 2. Total NOS activity, neuronal NOS activity and protein expression of neuronal (nNOS), endothelial (eNOS) and inducible (iNOS) isoforms in diencephalon isolated from Wistar-Kyoto (WKY) rats, spontaneously hypertensive rats (SHR) as well as from WKY and SHR chronically treated with captopril (WKY+CAP, SHR+CAP). Data are means \pm S.E.M. from 6-8 animals in each group. Protein expressions are expressed in percentage of WKY values obtained in the same assay. 


\section{Brainstem}

Total NOS activity

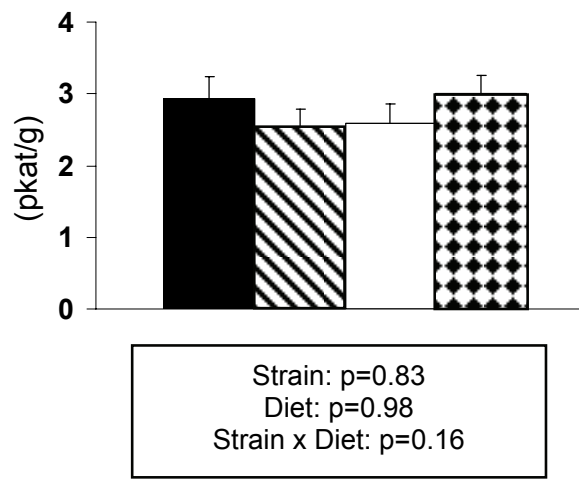

nNOS activity

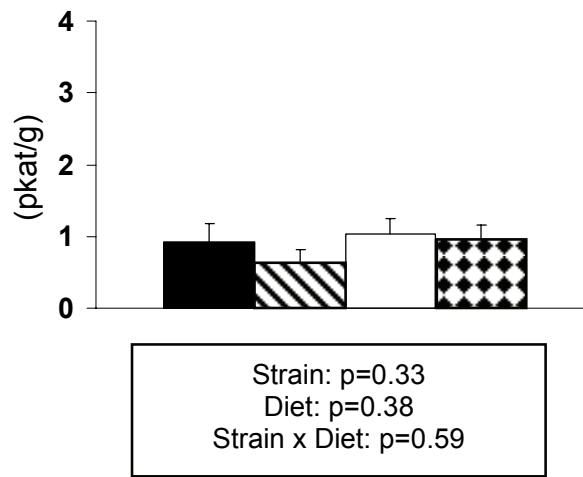

NOS protein expression
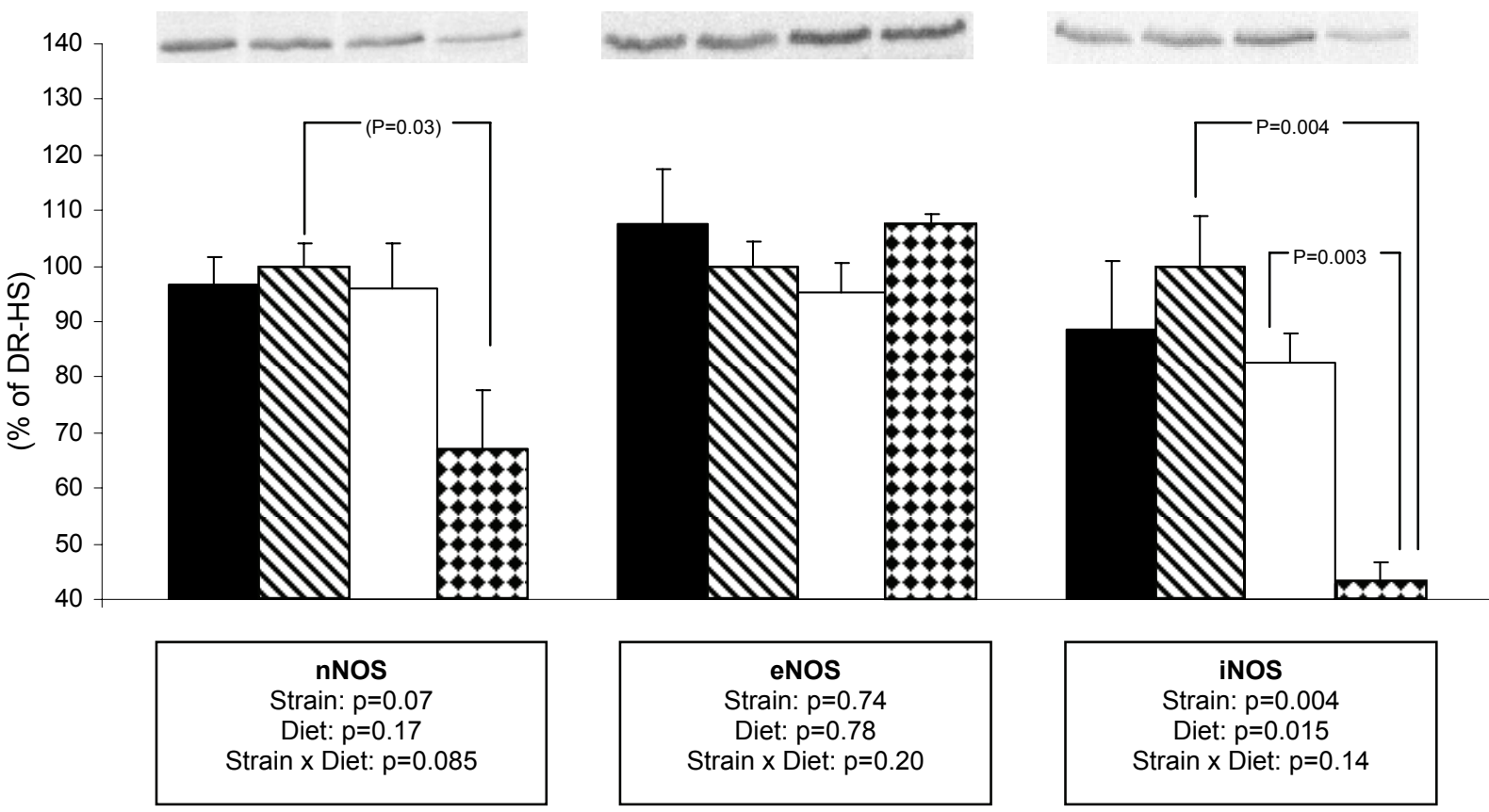

iNOS

Strain: $p=0.004$

Diet: $p=0.015$

Strain $x$ Diet: $p=0.14$

\section{DR-LS ND DR-HS \\ DS-LS DS-HS}

Fig. 3. Total NOS activity, neuronal NOS activity and protein expression of neuronal (nNOS), endothelial (eNOS) and inducible (iNOS) isoforms in brainstem isolated from salt-resistant (DR) and salt-sensitive (DS) Dahl which were fed either a low-salt (LS, $0.3 \% \mathrm{NaCl}$ ) or a high-salt diet (HS, $8 \% \mathrm{NaCl}$ ). Data are means \pm S.E.M.) from 6-7 animals in each group. Protein expressions are expressed in percentage of DR-HS values obtained in the same assay. 


\section{Diencephalon}

Total NOS activity

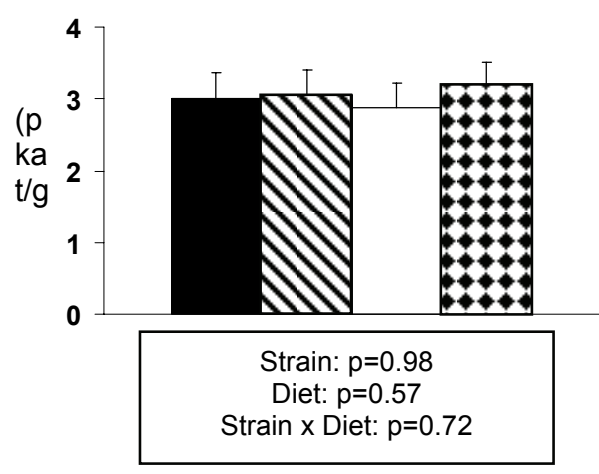

nNOS activity

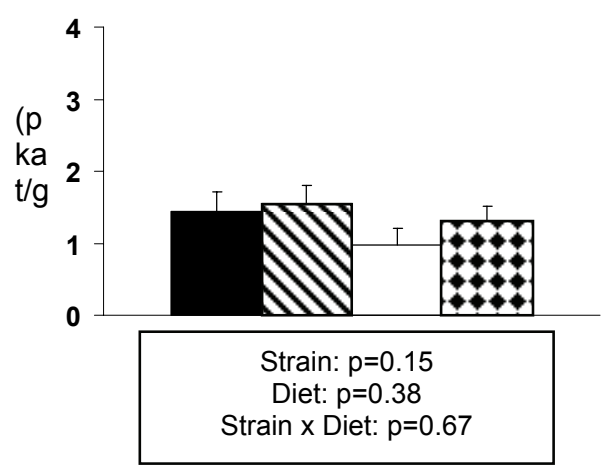

\section{NOS protein expression}
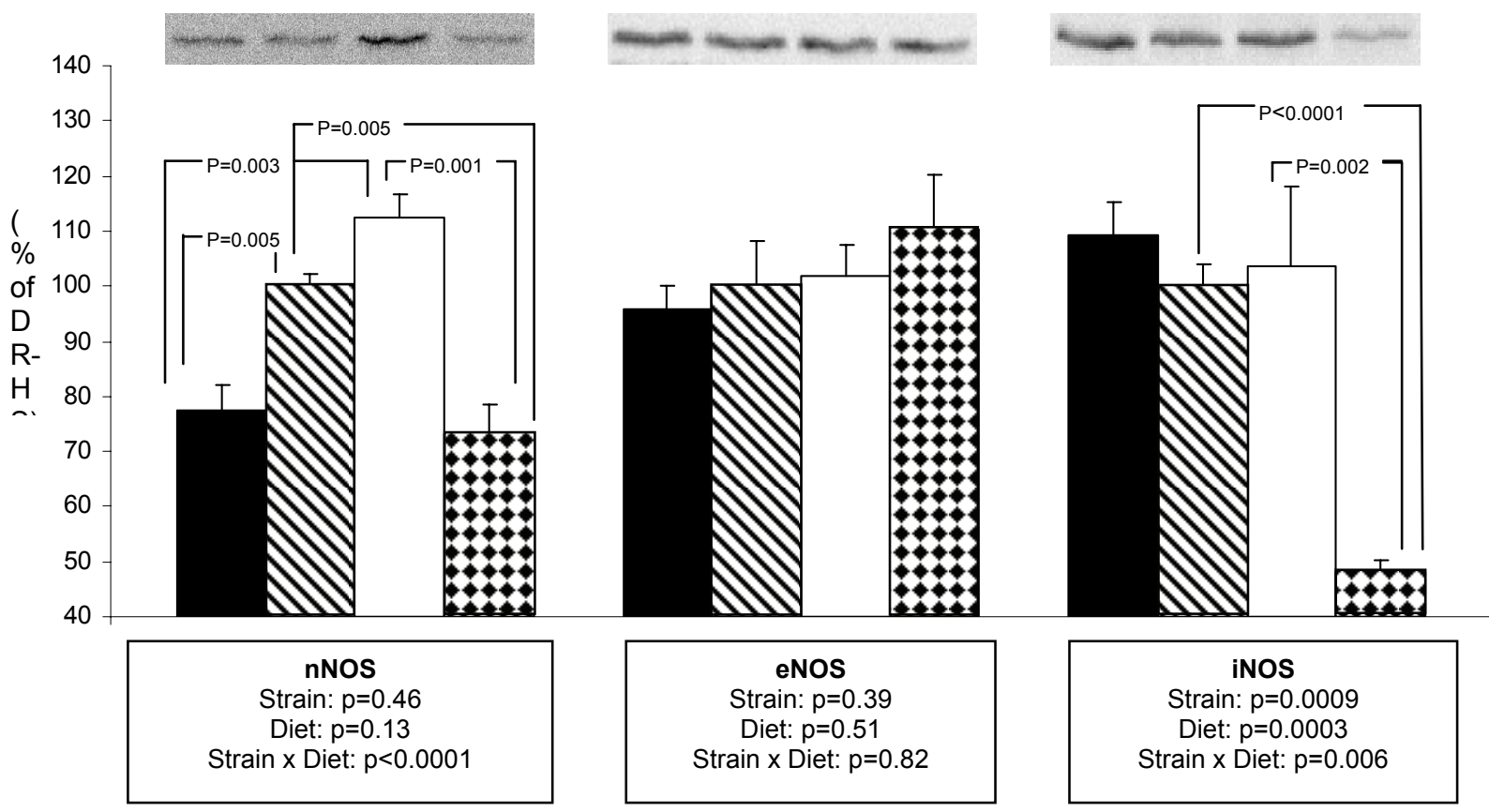

iNOS

Strain: $p=0.0009$

Diet: $p=0.0003$

Strain $x$ Diet: $p=0.006$

\section{DR-LS NV DR-HS}

DS-LS DS-HS

Fig. 4. Total NOS activity, neuronal NOS activity and protein expression of neuronal (nNOS), endothelial (eNOS) and inducible (iNOS) isoforms in diencephalon isolated from salt-resistant (DR) and salt-sensitive (DS) Dahl which were fed either a low-salt (LS, $0.3 \% \mathrm{NaCl}$ ) or a high-salt diet (HS, $8 \% \mathrm{NaCl}$ ). Data are means \pm S.E.M. from 6-7 animals in each group. Protein expressions are expressed in percentage of DR-HS values obtained in the same assay. 


\section{Kidney}

Total NOS activity

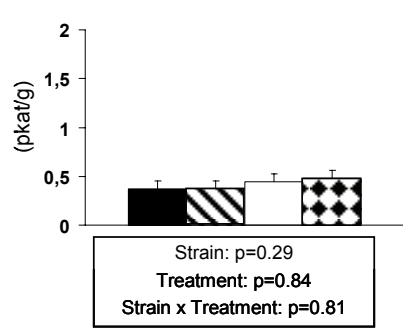

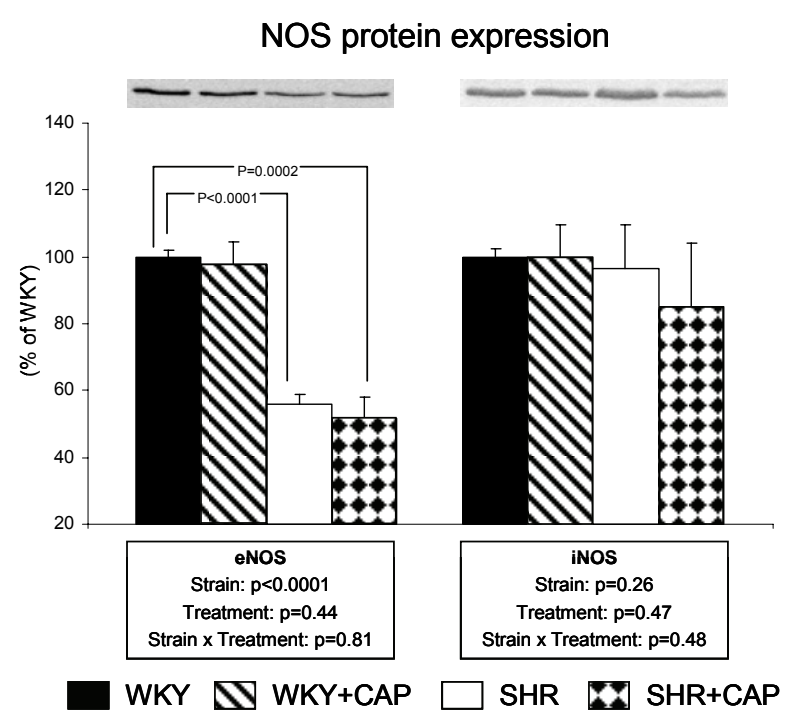

Fig. 5. Total NO synthase activity and protein expression of endothelial (eNOS) and inducible (iNOS) isoforms in the kidney from Wistar-Kyoto (WKY) rats, spontaneously hypertensive rats (SHR) as well as from WKY and SHR chronically treated with captopril (WKY+CAP, SHR+CAP) (upper panels) and from salt-resistant (DR) and salt-sensitive (DS) Dahl rats which were fed either a low-salt (LS, $0.3 \% \mathrm{NaCl}$ ) or a high-salt diet (HS, $8 \% \mathrm{NaCl}$ ) (lower panels). Data are means \pm S.E.M.. Protein expressions are expressed in percentage of WKY or DR-HS values obtained in the same assay.
Total NOS activity

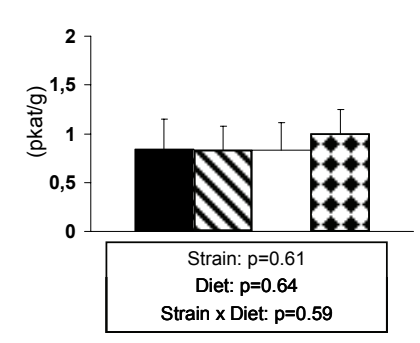

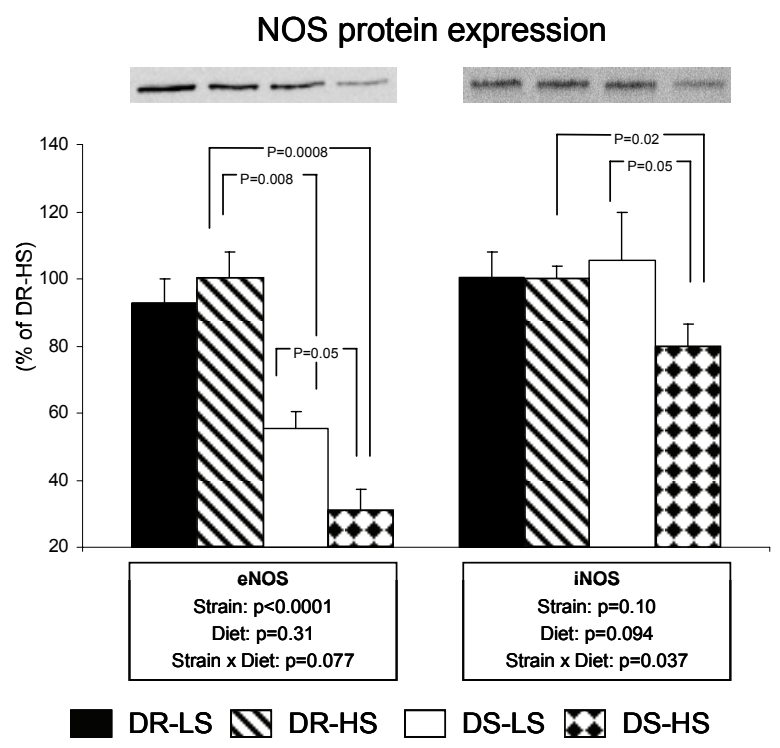

\section{Discussion}

Our study has demonstrated the reduction of nNOS and iNOS protein expression in the brainstem of both hypertensive models investigated, i.e. spontaneously hypertensive rats and salt-hypertensive Dahl rats. In brainstem of SHR the attenuated nNOS protein expression was accompanied by a significant decrease of total NOS activity as well as nNOS activity. Furthermore, we have observed in SHR that the full extent of nNOS and iNOS expression was restored by chronic captopril treatment, whereas the same treatment had a weaker effect on the expression of these NOS isoforms in agematched WKY rats. Similar alterations in the expression of the two NOS isoforms were also disclosed in the diencephalon of salt-hypertensive Dahl rats, but such changes were absent in the same brain structure of SHR. The above observations suggest that a high blood pressure in experimental hypertension is accompanied by diminished nNOS and iNOS protein expression in the brain regions which are involved in the control of sympathetic tone (Krukoff 1998, Osborn 2005). Sympathetic tone is considerably enhanced in rats with spontaneous (Head 1989, Paulis et al. 2007) or salt hypertension (Zicha et al. 2001, Leenen et al. 2002). Thus the attenuation of nNOS expression in the brainstem of both hypertensive models goes in parallel with the enhancement of sympathetic tone, whereas the restoration 
of nNOS expression in captopril-treated SHR is accompanied by a lowering of sympathetic tone (Paulis et al. 2007).

The occurrence of significant changes in nNOS and iNOS protein expression in diencephalon of salthypertensive Dahl rats but not in SHR might be related to the fact that diencephalon structures such as supraoptic and paraventricular hypothalamic nuclei were suggested to play a very important role in salt-sensing mechanisms (Orlov and Mongin 2007). Lesions of the paraventricular nucleus and surrounding tissues have prevented the rise of blood pressure in DS rats, while similar lesions in DR rats did not alter blood pressure (Ernsberger et al. 1985). These findings support the notion of Manning et al. (2001) who revealed decreased NO production in Dahl salt hypertensive rats due to a deficient nNOS protein, while NO produced by iNOS appeared to moderately decrease salt sensitivity. There are some findings confirming a significant reduction of nNOS expression in brain tissue after a chronic high salt intake (Castrop and Kurtz 2001, Ni and Vaziri 2001), while others reported increased nNOS expression and/or activity in the brain (Tandai-Hiruma et al. 2005, Toda et al. 2009).

Present data disclosed strain-dependent changes in total NOS activity and nNOS activity in brainstem of young adult SHR confirming a downregulated protein expression of nNOS and iNOS isoforms, which is in agreement with the finding of Pontieri et al. (1998). However, Qadri et al. (2003) have found elevated NOS activity not only in the hypothalamus but also in the brainstem of SHR aged 12-13 weeks. Nevertheless, similarly to that paper, our data showed that chronic treatment of SHR with captopril also normalized total NOS activity in the diencephalon, whereas the activity in the brainstem remained unchanged when compared to controls. It should be noted that at least in SHR, both NO production and the expression of particular NOS isoforms is highly dependent on the age of the animals studied. This is evident not only from the comparison of the present paper on 12-week-old rats with our previous study on older SHR aged 30 weeks (Hojná et al. 2007), but also from the developmental studies in SHR reported by Qadri et al. (2003) and Häuser et al. (2005). Facing decreased protein expression of nNOS in the brainstem of our salt-hypertensive animals one could expect that specific activity of nNOS isoform had to be elevated in hypertensive rats in order to maintain unchanged $\mathrm{NO}$ formation. Indeed, we have found unchanged nNOS activity in Dahl salt-sensitive rats compared to DR rats.
There are several possible explanations why this prediction need not always be confirmed. We must keep in mind that the in vitro findings on NO synthesis might be considerably different from the in vivo NO production. Moreover, reduced NO synthesis, which is consistent with a higher blood pressure level, may be caused by post-transductional modifications of the enzyme, interactions with other proteins or suboptimal concentrations of the substrate L-arginine or the cofactor tetrahydrobiopterin.

Increased sympathetic tone seems to be a consequence of the dysbalance between the action of angiotensin II and nitric oxide on vasomotor centers located in the brainstem (Krukoff 1998, Ito et al. 2002, Veerasingham and Raizada 2003). It should be noted that chronic antihypertensive effects of ACE inhibitors can be largely attributed to their central action because blood pressure lowering in SHR chronically treated with captopril is based upon the reduction of sympathetic vasoconstriction (Berecek et al. 1987, Hojná et al. 2007, Paulis et al. 2007). Similarly, chronic captopril administration attenuates the development of NOdeficient hypertension in L-NAME-treated rats (Pecháňová et al. 1997) by decreasing sympathetic vasoconstriction (Zicha et al. 2006) which belongs to principal pathogenetic mechanisms in this form of experimental hypertension besides the attenuation of NOdependent vasodilation (Pecháňová et al. 2004). These observations are fully compatible with the current knowledge on the influence exerted by angiotensin II and nitric oxide in the rostral-ventrolateral medulla on the control of sympathetic tone (Bergamaschi et al. 1999, 2002, Tsuchihashi et al. 2000).

The role of peripheral NO formation in blood pressure control might be more complicated than it was presumed some years ago. This is especially true for genetic hypertension where the reports are often contradictory (Minami et al. 1995, Hayakawa and Raij 1998, Kuneš et al. 2002, Pecháňová et al. 2006, Bernátová et al. 2007, Hojná et al. 2007, Kristek et al. 2007). Nevertheless, in our study there was an interesting observation of marked downregulation of eNOS protein expression in the kidney of both hypertensive models. In salt-sensitive Dahl rats the attenuation of eNOS expression was present even under the conditions of low salt intake and was further enhanced by high salt intake. In addition, we have found a suppression of iNOS expression in the kidney of Dahl rats with salt-induced hypertension. Reduced eNOS expression was also 
disclosed in the kidney of young adult SHR and this change persisted even after chronic captopril treatment which prevented the development of spontaneous hypertension in this strain. The attenuation of eNOS activity in renal medulla of both above mentioned hypertensive models was already reported by Hayakawa and Raij (1998). Zhou et al. (2008) also published a decreased nitric oxide bioavailability in DS rats on highsalt diet which was associated with increased renal oxidative stress as well as with downregulation of both eNOS activity and protein expression by $44 \%$. The suppressive influence of high salt intake on protein expression of eNOS and iNOS was also demonstrated in the kidney of Sprague-Dawley rats in which $8 \% \mathrm{NaCl}$ diet significantly increased blood pressure ( $\mathrm{Ni}$ and Vaziri 2001). There is a considerable evidence that NO produced by iNOS prevents the development of salt hypertension in salt-resistant Dahl rats and attenuates the salt-induced blood pressure rise in salt-sensitive Dahl rats (Rudd et al. 1999, Tan et al. 2000). This is in line with our finding of downregulated renal iNOS in salt hypertensive Dahl rats.

In conclusion, a comparison of spontaneous and salt-induced hypertension indicated that the changes in brain NO system of both hypertensive models are rather similar on the level of brainstem but not in the diencephalon. It is of importance to note that chronic captopril treatment of young adult SHR normalized altered expression of nNOS and iNOS just in the brainstem. It is evident that the decreased nNOS expression in the brainstem is associated with increased sympathetic tone. Protein expression changes in diencephalon disclosed only in salt-induced hypertension could indicate their very close relation to salt-sensing sites in the brain. Moreover, renal eNOS might also play an important role because its expression was lower in both hypertensive models. Our results support the importance of brain NO system in the long-term blood pressure regulation (probably through the control of sympathetic tone).

\section{Conflict of Interest}

There is no conflict of interest.

\section{Acknowledgements}

This work was supported by AV0Z 50110509, by Cardiovascular Research Center (1M0510) and by research grant of GA CR 305/08/0139. The technical assistance of Iva Nahodilová is highly appreciated.

\section{References}

BERECEK KH, KIRK KA, NAGAHAMA S, OPARIL S: Sympathetic function in spontaneously hypertensive rats after chronic administration of captopril. Am J Physiol 252: H796-H806, 1987.

BERGAMASCHI CT, BIANCARDI VC, LOPES OU, CAMPOS RR: Effects of angiotensin blockade in the rostral ventrolateral medulla on maintenance of hypertension induced by chronic L-NAME treatment. Brain Res 927 : 195-199, 2002.

BERGAMASCHI CT, CAMPOS RR, LOPES OU: Rostral ventrolateral medulla: a source of sympathetic activation in rats subjected to long-term treatment with L-NAME. Hypertension 34: 744-747, 1999.

BERNÁTOVÁ I, CSIZMADIOVÁ Z, KOPINCOVÁ J, PUZSEROVÁ A: Vascular function and nitric oxide production in chronic social-stress-exposed rats with various family history of hypertension. $J$ Physiol Pharmacol 58: 487-501, 2007.

BREDT DS, SNYDER SH: Isolation of nitric oxide synthetase, a calmodulin-requiring enzyme. Proc Natl Acad Sci USA 87: 682-685, 1990.

CABRERA CL, BEALER SL, BOHR DF: Central depressor action of nitric oxide is deficient in genetic hypertension. Am J Hypertens 9: 237-241, 1996.

CASTROP H, KURTZ A: Differential nNOS gene expression in salt-sensitive and salt-resistant Dahl rats. J Hypertens 19: 1223-1231, 2001.

DAMPNEY RA, HORIUCHI J, KILLINGER S, SHERIFF MJ, TAN PS, MCDOWALL LM: Long-term regulation of arterial blood pressure by hypothalamic nuclei: some critical questions. Clin Exp Pharmacol Physiol 32: 419$425,2005$. 
EDWARDS MA, LOXLEY RA, POWERS-MARTIN K, LIPSKI J, MCKITRICK DJ, ARNOLDA LF, PHILIPS JK: Unique levels of expression of N-methyl-D-aspartate receptor subunits and neuronal nitric oxide synthase in the rostral ventrolateral medulla of spontaneously hypertensive rat. Mol Brain Res 129: 33-43, 2004.

ERNSBERGER P, AZAR S, AZAR P: The role of the anteromedial hypothalamus in Dahl hypertension. Brain Res Bull 15: 651-656, 1985.

GEROVÁ M, MASANOVÁ C, PAVLÁSEK J: Inhibition of NO synthase in posterior hypothalamus increases blood pressure in rat. Physiol Res 44: 131-134, 1995.

HÄUSER W, SASSMANN A, QADRI F, JÖHREN O, DOMINIAK P: Expression of nitric oxide synthase isoforms in hypothalamo-pituitary-adrenal axis during the development of spontaneous hypertension in rats. Mol Brain Res 138: 198-204, 2005.

HAYAKAWA H, RAIJ L: Nitric oxide synthase activity and renal injury in genetic hypertension. Hypertension 31: 266-270, 1998.

HEAD RJ: Hypernoradrenergic innervation: its relationship to functional and hyperplastic changes in the vasculature of the spontaneously hypertensive rat. Blood Vessels 26: 1-20, 1989.

HOJNÁ S, KADLECOVÁ M, DOBEŠOVÁ Z, VALOUŠKOVÁ V, ZICHA J, KUNEŠ J: The participation of brain NO synthase in blood pressure control of adult spontaneously hypertensive rats. Mol Cell Biochem 297: 21-29, 2007.

HORN T, SMITH PM, MCLAUGHLIN BE, BAUCE L, MARKS GS, PITTMAN QJ, FERGUSON AV: Nitric oxide actions in paraventricular nucleus: cardiovascular and neurochemical implications. Am J Physiol 266: R306R313, 1994.

ITO S, KOMATSU K, TSUKAMOTO K, KANMATSUSE K, SVED AF: Ventrolateral medulla $\mathrm{AT}_{1}$ receptors support blood pressure in hypertensive rats. Hypertension 40: 552-559, 2002.

KAGIYAMA S, TSUCHIHASHI I, ABE I, FUJISHIMA M: Enhanced depressor response to nitric oxide in the rostral ventrolateral medulla of spontaneously hypertensive rats. Hypertension 31: 1030-1034, 1998.

KRISTEK F, KOPRDOVÁ R, CEBOVÁ M: Long-term effects of early administered sildenafil and NO donor on the cardiovascular system of SHR. J Physiol Pharmacol 58: 33-43, 2007.

KRUKOFF TL: Central actions of nitric oxide in regulation of autonomic function. Brain Res Rev 30: 52-65, 1999.

KRUKOFF TL: Central regulation of autonomic function: NO brakes? Clin Exp Pharmacol Physiol 25: 474-478, 1998.

KUNEŠ J, DOBEŠOVÁ Z, ZICHA J: Altered balance of main vasopressor and vasodepressor systems in rats with genetic hypertension and hypertriglyceridaemia. Clin Sci (Lond) 102: 269-277, 2002.

LEENEN FH, RUZICKA M, HUANG BS: The brain and salt-sensitive hypertension. Curr Hypertens Rep 4: 129-135, 2002.

LEWIS SJ, OHTA H, MACHADO B, BATES JN, TALMAN WT: Microinjection of S-nitrosocysteine into the nucleus tractus solitarii decreases blood pressure and heart rate via activation of soluble guanylate cyclase. Eur $J$ Pharmacol 202: 135-136, 1991.

MANNING RD JR, HU L, TAN DY, MENG S: Role of abnormal nitric oxide systems in salt-sensitive hypertension. Am J Hypertens 14: 68S-73S, 2001.

MINAMI N, IMAI Y, HASHIMOTO J, ABE K: Contribution of vascular nitric oxide to basal blood pressure in conscious spontaneously hypertensive rats and normotensive Wistar Kyoto rats. Clin Sci (Lond) 89: 177-182, 1995.

NI Z, VAZIRI ND: Effect of salt loading on nitric oxide synthase expression in normotensive rats. Am J Hypertens 14: 155-163, 2001.

ORLOV SN, MONGIN AA: Salt-sensing mechanisms in blood pressure regulation and hypertension. Am J Physiol 293: H2039-H2053, 2007.

OSBORN JW: Hypothesis: set-points and long-term control of arterial pressure. A theoretical argument for a long-term arterial pressure control system in the brain rather than the kidney. Clin Exp Pharmacol Physiol 32: 384-393, 2005.

PAULIS L, LÍŠKOVÁ S, PINTÉROVÁ M, DOBEŠOVÁ Z, KUNEŠ J, ZICHA J: Nifedipine-sensitive noradrenergic vasoconstriction is enhanced in spontaneously hypertensive rats: the influence of chronic captopril treatment. Acta Physiol 191: 255-266, 2007. 
PECHÁŇOVÁ O, BERNÁTOVÁ I, PELOUCH V, ŠIMKO F: Protein remodelling of the heart in NO-deficient hypertension: the effect of captopril. J Mol Cell Cardiol 29: 3365-3374, 1997.

PECHÁŇOVÁ O, DOBEŠOVÁ Z, ČEJKA J, KUNEŠ J, ZICHA J: Vasoactive systems in L-NAME hypertension: the role of inducible NO synthase. J Hypertens 22: 167-173, 2004.

PECHÁŇOVÁ O, ZICHA J, KOJŠOVÁ S, DOBEŠOVÁ Z, JENDEKOVÁ L, KUNEŠ J: Effect of chronic Nacetylcysteine treatment on the development of spontaneous hypertension. Clin Sci (Lond) 110: 235-242, 2006.

PLOCHOCKA-ZULINSKA D, KRUKOFF TL: Increase gene expression of neuronal nitric oxide synthase in brain of adult spontaneously hypertensive rats. Mol Brain Res 48: 291-297, 1997.

PONTIERI V, VENEZUELA MK, SCAVONE C, MICHELINI LC: Role of endogenous nitric oxide in the nucleus tratus solitarii on baroreflex control of heart rate in spontaneously hypertensive rats. J Hypertens 16: 19931999, 1998.

QADRI F, ARENS T, SCHWARZ E-C, HÄUSER W, DENDORFER A, DOMINIAK P: Brain nitric oxide synthase activity in spontaneously hypertensive rats during the development of hypertension. $J$ Hypertens 21: 16871694, 2003.

RUDD MA, TROLLIET M, HOPE S, SCRIBNER AW, DAUMERIE G, TOOLAN G, CLOUTIER T, LOSCALZO J: Salt-induced hypertension in Dahl salt-resistant and salt-sensitive rats with NOS II inhibition. Am J Physiol 277: H732-H739, 1999.

TAN DY, MENG S, CASON GW, MANNING RD: Mechanisms of salt-sensitive hypertension: role of inducible nitric oxide synthase. Am J Physiol 279: R2297-R2303, 2000.

TANDAI-HIRUMA M, HORIUCHI J, SAKAMOTO H, KEMURIYAMA T, HIRAKAWA H, NISHIDA Y: Brain neuronal nitric oxide synthase neuron-mediated sympathoinhibition is enhanced in hypertensive Dahl rats. $J$ Hypertens 23: 825-834, 2005.

TODA N, AYAJIKI K, OKANUTA T: Control of systemic and pulmonary blood pressure by nitric oxide formed through neuronal nitric oxide synthase. J Hypertens 27: 1929-1940, 2009.

TSENG CJ, LIU HY, LIN HC, GER LP, TUNG CS, YEN MH: Cardiovascular effects of nitric oxide in the brain stem nuclei of rats. Hypertension 27: 36-42, 1996.

TSUCHIHASHI T, KAGIYAMA S, MATSUMURA K, LIN Y, ABE I, FUJISHIMA M: Cardiovascular responses to glutamate and angiotensin II in ventrolateral medulla of hypertension induced by chronic inhibition of nitric oxide. Hypertens Res 23: 359-364, 2000.

VEERASINGHAM SJ, RAIZADA MK: Brain renin-angiotensin system dysfunction in hypertension: recent advances and perspectives. Br J Pharmacol 139: 191-202, 2003.

ZHOU MS, SCHUMAN IH, JAIMES EA, RAIJ L: Renoprotection by statins is linked to a decrease in renal oxidative stress, TGF-beta, and fibronectin with concomitant increase in nitric oxide bioavailability. Am J Physiol 295: F53-F59, 2008.

ZICHA J, DOBEŠOVÁ Z, KUNEŠ J: Antihypertensive mechanisms of chronic captopril or N-acetylcysteine treatment in L-NAME hypertensive rats. Hypertens Res 29: 1021-1027, 2006.

ZICHA J, DOBEŠOVÁ Z, KUNEŠ J: Relative deficiency of nitric oxide-dependent vasodilation in salt-hypertensive Dahl rats: the possible role of superoxide anions. J Hypertens 19: 247-254, 2001. 